prior decision of the chancellor in 2011 where the chancellor had had occasion to criticise him. The chancellor directed that the architect had 21 days to make written submissions as to whether the chancellor should recommend to the DAC that his name be removed from the list of approved architects.

The chancellor noted that most of the court costs had been accrued by the need for a hearing to consider the conflicting evidence between the petitioners and the architect. That dispute had been resolved in the petitioners' favour and the architect was found to have been less than candid in his dealings with the DAC and less than truthful in his evidence to the court. The court costs would be paid by the petitioners with a two-thirds contribution from the architect, subject to the right of the parties to make submissions in support of an alternative costs order. [RA]

doi:10.1017/So956618X18000868

\title{
R (Adath Yisroel Burial Society \& Anor) v HM Senior Coroner for Inner North London
}

Divisional Court: Singh LJ and Whipple J, 27 April 2018 [2018] EWHC 969 (Admin)

Refusal by coroner to prioritise Jewish and Muslim burials - Equality Act 2010 Article 9 ECHR

The claimants challenged the lawfulness of the policy adopted by the Senior Coroner for Inner North London, Ms Mary Hassell, that no death will be prioritised in any way over any other because of the religion of the deceased or family, either by the coroner's officers or by coroners - described variously by Ms Hassell as a 'cab rank rule' and 'an equality protocol' - on the grounds that it breached Article 9 of the European Convention on Human Rights (ECHR) (thought, conscience and religion) and Article 14 (discrimination), that it was indirect discrimination contrary to section 19 of the Equality Act 2010 and that it breached the public sector equality duty (PSED) in section 149 of that Act. The Chief Coroner, as an interested party, submitted that, as a matter of public law and quite apart from the Human Rights Act 1998, the policy was unlawful because it fettered Ms Hassell's discretion and was irrational. Ms Hassell's particular concern was that the Jewish families represented before the court were being prioritised over other families by her coroner's officers and she wished to stop the practice because she argued that what causes most distress for all families is a delay in decision-making and notification of that decision. She maintained that her policy took account of Articles 8, 9 and 14 ECHR and the relevant sections of the Equality Act.

The court concluded that the coroner's power in the present case was akin to a power derived from statute, that the principle against fettering a discretion 
therefore applied and that the policy breached that principle. As to the issue of irrationality, Ms Hassell accepted that cases such as deaths that were the subject of homicide investigations and organ donations had to be given priority, so the policy was not a strict cab rank rule because not every case was dealt with in chronological order, nor was it capable of rational justification. As to Article 9 ECHR and the Equality Act 2010, Article 9 required not that there should be any favouritism, whether in favour of religious belief in general or in favour of any particular religious faith, but that there should be a fair balance struck between the rights and interests of different people in society. Ms Hassell's policy failed to do that. Moreover, as a matter of domestic law, prioritisation of some deaths for religious reasons would not be unlawful; on the contrary, it would be consistent with section 158 of the Equality Act 2010. The fact that other coroners did not operate the same strict policy did not seem to cause undue difficulties, nor could the policy be justified by an argument of limited resources. It therefore violated the principle of equal treatment in Article 14 ECHR and also discriminated against Jews and Muslims, though it was not in breach of the PSED. The court held as follows:

(1) A Coroner cannot lawfully exclude religious reasons for seeking expedition of decisions by that Coroner, including the Coroner's decision whether to release a body for burial.

(2) A Coroner is entitled to prioritise cases, for religious or other reasons, even where the consequence of prioritising one or some cases may be that other cases will have to wait longer for a decision. It is not necessary that all cases are treated in the same way or in strictly chronological sequence.

(3) Whether to accord one case priority over another or others is for the Coroner to determine. The following further points apply:

a) It is in principle acceptable for the Coroner to implement a policy to address the circumstances when priority will or may be given, so long as that policy is flexible and enables all relevant considerations to be taken into account.

b) The availability of resources may be a relevant consideration in drawing up that policy or in making the decision in any individual case but limitations on resources does not justify discrimination.

(4) It would be wrong for a Coroner to impose a rule of automatic priority for cases where there are religious reasons for seeking expedition.

The claim succeeded on all grounds except that based on the PSED. The court granted a declaration that the current policy was unlawful and made a quashing order setting it aside. [Frank Cranmer] 